\title{
Polymorphic variants in vitamin D signaling pathway genes and the risk of endometriosis-associated infertility
}

\author{
MALGORZATA SZCZEPAŃSKA ${ }^{1}$, ADRIANNA MOSTOWSKA ${ }^{2}$, PRZEMYSLAW WIRSTLEIN ${ }^{1,2}$, \\ JANA SKRZYPCZAK ${ }^{1}$, MATTHEW MISZTAL ${ }^{2}$ and PAWEŁ P. JAGODZIŃSKI ${ }^{2}$ \\ ${ }^{1}$ Department of Obstetrics, Gynecology and Gynecological Oncology, Division of Reproduction; \\ ${ }^{2}$ Department of Biochemistry and Molecular Biology, Poznań University of Medical Sciences, Poznań 60-781, Poland
}

Received November 4, 2014; Accepted July 28, 2015

DOI: $10.3892 / \mathrm{mmr} .2015 .4309$

\begin{abstract}
It has recently been reported that vitamin D blood plasma levels are associated with reduced risk of endometriosis. The present study aimed to investigate whether the vitamin D binding protein $(G C)$, vitamin $\mathrm{D}$ receptor $(V D R)$, and retinoid $\mathrm{X}$ receptor $(R X R)$ gene variants may be genetic risk factors for endometriosis-associated infertility. The subjects consisted of 154 women with endometriosis-associated infertility and 347 controls. Using polymerase chain reaction restriction fragment length polymorphism and high resolution melt techniques, the $G C$ rs1155563, rs2298849 and rs7041; RXRA rs10881578, rs10776909 and rs749759; VDR BsmI rs1544410; and FokI rs2228570 single nucleotide polymorphisms (SNPs) were investigated in the patients with endometriosis and the healthy controls. The results indicated that no significant differences were observed between the genotype and allele frequencies of all experimental SNPs in the vitamin D signaling pathway genes in women with endometriosis-associated infertility and controls. However, a significant association was present between the A-T haplotype, consisting of VDR rs 1544410 and rs222857 minor alleles, and endometriosis-associated infertility $[\mathrm{OR}=1.659(1.122-2.453), \mathrm{P}=0.011]$. The results of the present study suggested that $V D R$ gene variants act as genetic risk factors for endometriosis-associated infertility.
\end{abstract}

\section{Introduction}

Endometriosis is a gynecological disorder that affects $~ 10 \%$ of women of reproductive age (1). The disease prevalence increases to $30-40 \%$ among infertile women $(2,3)$. The development and persistence of endometriosis is associated with alterations in the immune and endocrine systems $(3,4)$. The exact cause of endometriosis and accompanied infertility remains elusive $(3,4)$.

Correspondence to: Dr Paweł P. Jagodzinski, Department of Biochemistry and Molecular Biology, Poznań University of Medical Sciences, 6 Święcickiego Street, Poznań 60-781, Poland

E-mail: pjagodzi@am.poznan.pl

Key words: polymorphisms, endometriosis, infertility
Development of endometriosis is hypothesized to be associated with genetic predisposition factors (5). The heritable traits of endometriosis have previously been reported, with a 5-7-fold increased risk of endometriosis development in first-degree relatives (6) There are numerous recognized endometriosis susceptibility genes, which are associated with steroid hormone action, immune response, oxidative stress, glucose homeostasis, vascular and tissue remodeling, and apoptosis $(7,8)$. Endometriosis is characterized by the abnormal survival and growth of endometrial tissue in the abdominal organs (1), which are resistant to apoptosis $(8,9)$. Among the critical factors affecting apoptosis in endometriosis, it has been proposed that survivinl may inhibit apoptosis (10). A recent study reported that increased blood plasma levels of vitamin D are associated with reduced risk of endometriosis, indicating that vitamin $\mathrm{D}$ has a beneficial role in the disease (11). Vitamin D is able to inhibit cell proliferation and trigger apoptosis of various types of cancer cell in animal models, as well as in vitro (12). Furthermore, the effects of vitamin D on malignant cells is mediated by inhibition of survivin overexpression (13).

Several proteins mediate the biological effects of vitamin $\mathrm{D}$, 1,25-dihydroxyvitamin D3 $\left[1,25(\mathrm{OH})_{2} \mathrm{D}_{3}\right]$, in humans. Among these are vitamin $\mathrm{D}$ binding protein (VDBP), vitamin $\mathrm{D}$ receptor (VDR), and retinoid $\mathrm{X}$ receptor (RXR) (14-16).

VDBP is encoded by the $G C$ gene and is a protein involved in the blood transport of vitamin D and its metabolites (14). VDR binds to RXR, and these heterodimers interact with DNA to induce vitamin $\mathrm{D}$ gene expression in target cells $(15,16)$.

A previous study demonstrated that $G C$ single nucleotide polymorphisms (SNP) may affect blood plasma vitamin D levels (17). The VDR gene also exists in certain genetic variants, which may modulate the biological effect of vitamin D in target cells (18). Furthermore, RXRA gene variants are associated with the development of certain tumor types (19). In order to investigate whether $R X R A, G C$ and $V D R$ gene variants may be genetic risk factors of endometriosis-associated infertility, eight SNPs of these genes located in various blocks of linkage disequilibrium (LD) were selected for the present study.

\section{Materials and methods}

Patients and controls. Peripheral blood samples from women with endometriosis and healthy women were obtained from 
the Gynecologic and Obstetrical University Hospital, Division of Reproduction at Poznań University of Medical Sciences (Poznań, Poland). A total of 154 subjects were primary infertile women with endometriosis, and 347 women were used as fertile controls (Table I). The stage of endometriosis was assessed according to the revised classification of the American Society for Reproductive Medicine (20). The inclusion and exclusion criteria for the women with endometriosis and the fertile control women have been previously described (21). The fertile women assigned to the control group were examined for the cause of chronic pelvic pain in the absence of any pelvic abnormalities, as determined by laparoscopy. The controls were diagnosed as having varicose veins in the pelvic floor but no signs of past or present inflammation. Patients and controls were matched by age and were all Caucasian of Polish descent (Table I). Written informed consent was obtained from all participating individuals, and the present study was approved by the Local Ethical Committee of the Poznan University of Medical Sciences.

Genotyping. Genomic DNA was obtained from peripheral blood leucocytes by salt extraction, as previously described (22). The DNA samples were subsequently genotyped for the eight SNPs in the RXRA, GC and $V D R$ genes (Table II). The SNPs were selected with the use of the genome browsers of the International HapMap Consortium (http:// www.hapmap.org/index.html.en), the UCSC genome browser (http://genome.ucsc.edu), and the dbSNP database (http://www. ncbi.nlm.nih.gov/projects/SNP/). The SNPs were selected based on functional significance, distinct location in the LD blocks, and minor allele frequency $(>0.1)$ in the Caucasian population. Genotyping of the $G C$ rs 1155563 and rs 2298849 and $R X R A$ rs10881578 and rs10776909 SNPs was conducted by high resolution melting (HRM) using a LightCycler 480 system (Roche Diagnostics GmbH, Mannheim, Germany), with 5X HOT FIREPol ${ }^{\circledR}$ EvaGreen $^{\circledR}$ quantitative polymerase chain reaction (PCR) Mix (Solis BioDyne, Tartu, Estonia). Genotyping of the GC rs7041, VDR BsmI rs1544410, FokI rs2228570, and $R X R A$ rs749759, SNPs were performed by PCR followed by appropriate restriction enzyme digestion (Thermo Fisher Scientific, Inc., Waltham, MA, USA) with PCR-restriction fragment length polymorphism (PCR-RFLP) according to the manufacturer's instructions (Thermo Fisher Scientific). The primer sequences and thermocycling conditions of the HRM and PCR-RFLP are presented in Table II. Genotyping quality was evaluated by repeated genotyping of $15 \%$ randomly selected samples.

Statistical analysis. For each SNP, the Hardy-Weinberg equilibrium (HWE) was assessed by Pearson's goodness-of-fit $\chi^{2}$ statistical test. The differences in allele and genotype frequencies between the patients and the controls were determined using standard $\chi^{2}$ or Fisher tests. The odds ratio (OR) and associated $95 \%$ confidence intervals (95\% CI) were also calculated. The data were analyzed under recessive and dominant inheritance models. For the additive inheritance model, the SNPs were tested for association with endometriosis using the Cochran-Armitage trend test. To adjust for the multiple testing, a Bonferroni correction was used. Haplotype based association analysis was performed using the UNPHASED
Table I. Clinical characteristics of women with endometriosis and controls.

\begin{tabular}{lcc}
\hline Characteristic & Endometriosis & Controls \\
\hline Number & 154 & 347 \\
Age (years) & $33(20-42)^{\mathrm{a}}$ & $33(19-39)^{\mathrm{a}}$ \\
Parity & NA & $1(1-4)^{\mathrm{a}}$ \\
$\begin{array}{l}\text { Duration of infertility (years) } \\
\text { rASRM (stage) }\end{array}$ & $3(1-7)^{\mathrm{a}}$ & NA \\
Stage I ( $\mathrm{n}=85)$ & & \\
Stage II (n=69) & NA & NA \\
\hline
\end{tabular}

${ }^{a}$ Median range; rASRM, revised American Society for Reproductive Medicine classification; NA, not applicable.

3.1.5 program (http://sourceforge.net/projects/unphased/files/ unphased-3.1.5.zip/download) with the following analysis options: All window sizes, full model and uncertain haplotype (23). The P-values for the global and individual tests of haplotype distribution between cases and controls were determined. Statistical significance was assessed using 1,000-fold permutation testing. $\mathrm{P}<0.05$ was considered to indicate a statistically significant difference.

High order gene-gene interactions among all tested polymorphic loci were investigated using a multifactor dimensionality reduction (MDR) approach with MDR version 2.0 $\beta 5$ (http://www.epistasis.org/). A detailed explanation on the MDR method has been described previously (24). Based on the obtained testing balanced accuracy and cross-validation consistency values, the best statistical gene-gene interaction models were established. A 1,000-fold permutation test was used to assess the statistical significance of the MDR models (MDR permutation testing module $0.4 .9 \alpha$ ).

\section{Results}

Prevalence of the GC, RXRA and VDR SNPs in women with endometriosis-associated infertility. The distribution of the $R X R A, G C$ and $V D R$ genotypes did not display deviation from the HWE between patients and control groups ( $\mathrm{P}>0.05)$. The number of genotypes, OR, and 95\% CI evaluation for the eight $G C, R X R A$ and $V D R$ SNPs are shown in Table III. No association was reported between the $G C, R X R A$ and $V D R$ SNPs of either the dominant or recessive inheritance models and endometriosis-associated infertility. The statistical significance of the multiple testing determined by correction of SNPs was $\mathrm{P}=0.00625$. The lowest $\mathrm{P}$-values of the trend test were demonstrated for VDR FokI rs2228570 and RXRA rs749759 in women with endometriosis-associated infertility $\left(\mathrm{P}_{\text {trend }}=0.044\right.$ and $\mathrm{P}_{\text {trend }}=0.076$, respectively).

Association of GC, RXRA, and VDR haplotypes with endometriosis-associated infertility. Haplotype analysis of the $G C, R X R A$ and VDR SNPs is presented in Table IV. A significant association was demonstrated to exist between the A-T $V D R$ (rs1544410 and rs2228570) haplotype and endometri- 


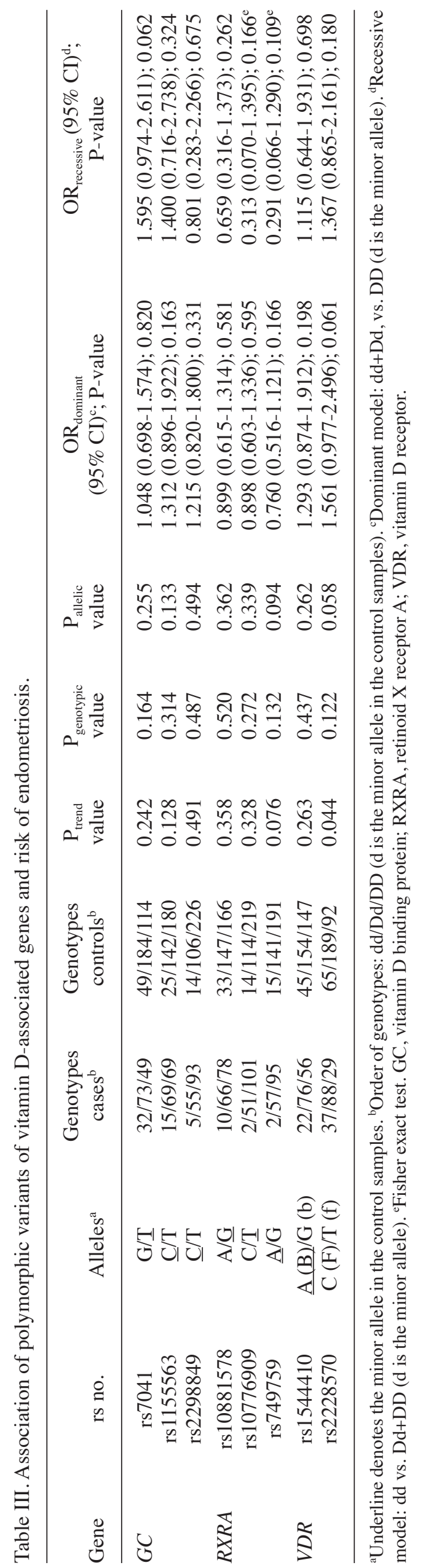

osis-associated infertility [OR=1.659 (1.122-2.453), $\mathrm{P}=0.011]$. However, no other associations between $V D R$ haplotypes and endometriosis were demonstrated. Furthermore, there was no association between SNP $G C$ and $R X R A$ and increased risk of endometriosis-associated infertility. The empirical $5 \%$ quantile of the best P-value following 1,000 permutations was 0.01487 for $G C, 0.01273$ for $R X R A$ and 0.02565 for $V D R$ haplotypes.

Analysis of gene-gene interactions between the GC, RXRA and VDR polymorphisms. Exhaustive MDR analysis evaluating 2-4 loci combinations of all investigated SNPs for each comparison did not indicate statistical significance in predicting susceptibility to endometriosis-associated infertility (Table V). The best combination of possibly interactive polymorphisms was observed for $G C$ rs7041 and rs2298849, and $V D R$ rs2228570 (testing balanced accuracy, 0.496; cross validation consistency, $70 \%$; permutation test $\mathrm{P}=0.895)$.

\section{Discussion}

The role of vitamin $\mathrm{D}$ in maintaining calcium and phosphorus homeostasis and bone health has been well-established $(18,25)$. However, numerous studies have demonstrated the contribution of vitamin D to several other aspects of health, including human reproduction (26). Vitamin D regulates the expression of numerous genes, including genes associated with steroidogenesis of sex hormones in female reproductive tissues, which also extends to estradiol and progesterone $(26,27)$. Previous studies on humans and animals demonstrated that low vitamin D levels are associated with reduced fertility, poor in vitro fertilization outcome, and polycystic ovary syndrome $(27,28)$. In addition, the predicted plasma $25(\mathrm{OH})$ $\mathrm{D}_{3}$ levels have been observed to be inversely associated with endometriosis $(27,11)$.

The role of vitamin D in the development and progression of endometriosis has also been extensively investigated in animal models. Abbas et al (29) reported the regression of endometriotic implants treated with vitamin D3 in a rat model (29). Recently, Yildirim et al (30) demonstrated the regression of endometriosis in rats treated with vitamin $\mathrm{D}$, as well as associated changes in vascular endothelial growth factor, matrix metalloproteinase- 9 and tissue inhibitor of metalloproteinase-2 expression levels (29).

Polymorphisms located in genes encoding proteins mediated by vitamin D may be risk factors for endometriosis and infertility. The results of the present study demonstrated that $G C, R X R A$ and $V D R$ SNPs were not separate risk factors for endometriosis-associated infertility. A previous study reported that no association was observed between FokI and BmsI $V D R$ polymorphisms and endometriosis and/or infertility in Brazilian women (31). However, in the present genetic study, the A-T BmsI/FokI VDR haplotype was a significant risk factor for endometriosis-associated infertility.

The function of BsmI and FokI SNPs on the biological effects of VDR have been extensively studied $(18,32-34)$. The BsmI polymorphism may change the length of the polyadenylate sequence in VDR transcript (18). Recently, Luo et al (32) demonstrated that the BsmI polymorphism 


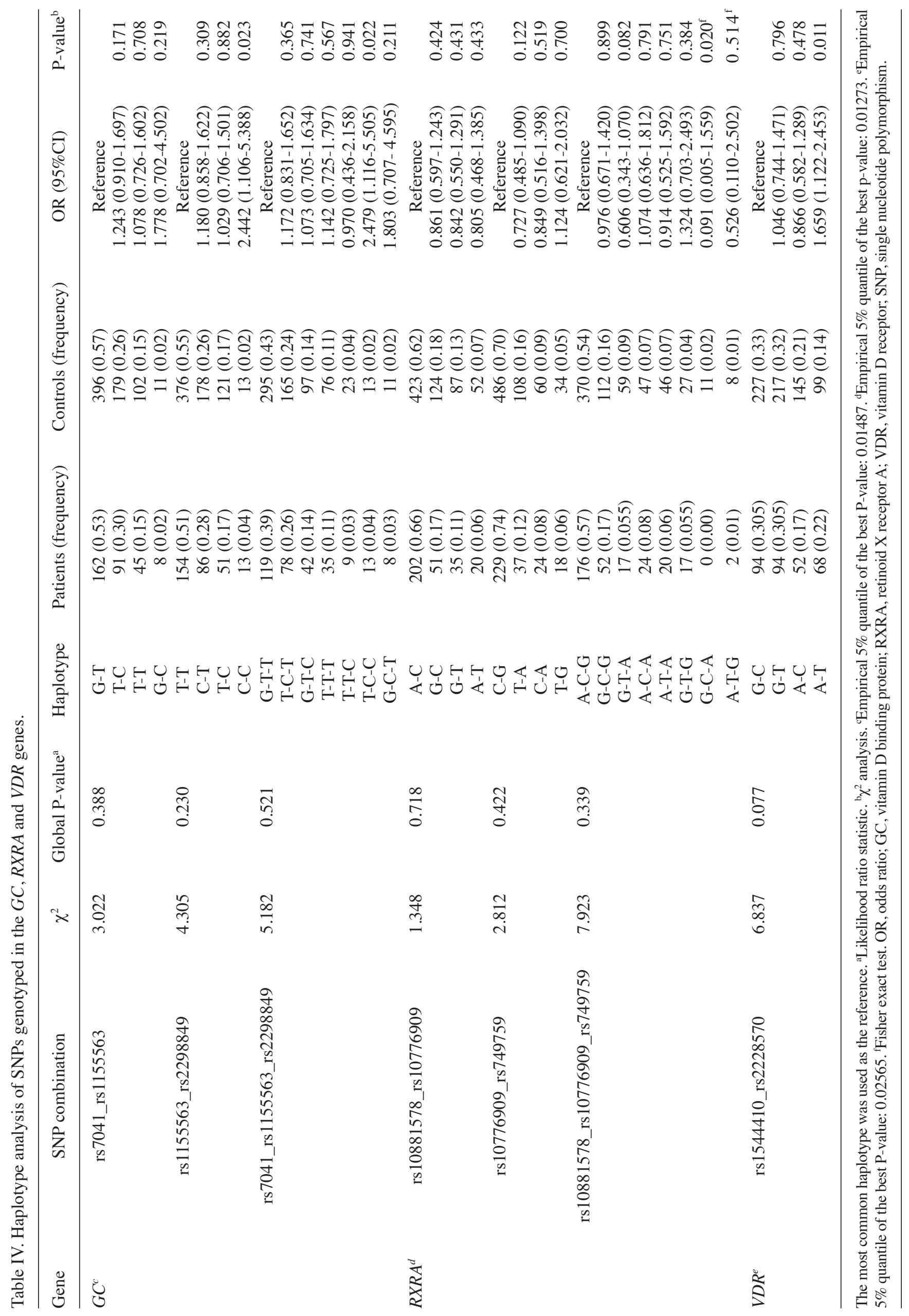


significantly reduced the mRNA expression levels of VDR in carriers of the A (B) allele, as compared with subjects carrying the GG (bb) genotype (32). The FokI SNP gives rise to two protein forms: A long VDR, encoded by the minor allele form (ATG; f), which contains three additional amino acids, and a shorter form, encoded by (ACG; F) (33). The longer form exhibits 1.7x less efficiency than the shorter form (33). Furthermore, high frequency of the VDR (ATG) (f) allele was associated with a decrease in Th1 immune response (17). A previous study on the role of the FokI SNP demonstrated the presence of increased vitamin D levels in carriers of the TT (ff) genotype, as compared with carriers of the CC (FF) genotype (34).

The presence of the VDR in normal endometrium and endometriotic implants has been demonstrated (35). Furthermore, women suffering from endometriosis express higher levels of VDRs in their endometrial tissue $(35,36)$. In addition, VDRs have been detected in female reproductive tissues, including the ovary, uterus and placenta (37). The expression levels of VDR may also have an important role in the development of endometriosis. Mariani et al (38) demonstrated that the VDR agonist elocalcitol exerts protective effects on the implantation and organization of transferred endometriotic implants in murine model of endometriosis.

In conclusion, the present study demonstrated that the A-T (B-f) VDR haplotype may be a risk factor for endometriosis-associated infertility. However, in order to further validate the role of this haplotype in endometriosis-associated infertility, similar studies must be conducted in independent ethnicities and in women with idiopathic infertility.

\section{Acknowledgements}

The present study was supported by a grant from the Poznan University of Medical Sciences (grant. no. 502-01-01124182 -07474). The authors of the present study are grateful for the technical assistance of Ms. Sylwia Matuszewska.

\section{References}

1. Mahmood TA and Templeton A: Prevalence and genesis of endometriosis. Hum Reprod 6: 544-549, 1991.

2. Meuleman C, Vandenabeele B and Fieuws S: High prevalence of endometriosis in infertile women with normal ovulation and normospermic partners. Fertil Steril 92: 68-74, 2009.

3. de Ziegler D, Borghese B and Chapron C: Endometriosis and infertility: Pathophysiology and management. Lancet 376: 730-738, 2010

4. Brosens I and Benagiano G: Endometriosis, a modern syndrome. Indian J Med Res 133: 581-593, 2011.

5. Montgomery GW, Zondervan KT and Nyholt DR: The future for genetic studies in reproduction. Mol Hum Reprod 20: 1-14, 2014.

6. Bischoff FZ and Simpson JL: Heritability and molecular genetic studies of endometriosis. Hum Reprod Update 6: 37-44, 2000.

7. Montgomery GW, Nyholt DR, Zhao ZZ, Treloar SA, Painter JN Missmer SA, Kennedy SH and Zondervan KT: The search for genes contributing to endometriosis risk. Hum Reprod Update 14: 447-457, 2008.

8. Braun DP, Ding J, Shaheen F, Willey JC, Rana N and Dmowski WP: Quantitative expression of apoptosis-regulating genes in endometrium from women with and without endometriosis. Fertil Steril 87: 263-268, 2007.

9. Gebel HM, Braun DP, Tambur A, Frame D, Rana N and Dmowski DP: Spontaneous apoptosis of endometrial tissue is impaired in women with endometriosis. Fertil Steril 69: 1042-1047, 1998. 
10. Fujino K, Ueda M, Takehara M, Futakuchi H, Kanda K, Yamashita Y, Terai Y and Ueki M: Transcriptional expression of survivin and its splice variants in endometriosis. Mol Hum Reprod 12: 383-388, 2006.

11. Harris HR, Chavarro JE, Malspeis S, Willett WC and Missmer SA: Dairy-food, calcium, magnesium and vitamin D intake and endometriosis: A prospective cohort study. Am J Epidemiol 177: 420-430, 2013

12. Basit S: Vitamin D in health and disease: A literature review. $\mathrm{Br}$ J Biomed Sci 70: 161-172, 2013.

13. Li F, Ling X, Huang H, Brattain L, Apontes P, Wu J, Binderup L and Brattain MG: Differential regulation of survivin expression and apoptosis by vitamin D3 compounds in two isogenic MCF-7 breast cancer cell sublines. Oncogene 24: 1385-1395, 2005.

14. Daiger SP, Schanfield MS and Cavalli-Sforza LL: Group-specific component $(\mathrm{Gc})$ proteins bind vitamin $\mathrm{D}$ and 25 hydroxyvitamin $\mathrm{D}$. Proc Natl Acad Sci USA 72: 2076-2080, 1975.

15. Yang L, Ma J, Zhang X, Fan Y and Wang L: Protective role of the vitamin D receptor. Cell Immunol 279: 160-166, 2012

16. Zhang J, Chalmers MJ, Stayrook KR, Burris LL, Wang Y, Busby SA, Pascal BD, Garcia-Ordonez RD, Bruning JB, Istrate MA, et al: DNA binding alters coactivator interaction surfaces of the intact VDR-RXR complex. Nat Struct Mol Biol 18: 556-563, 2011.

17. Larcombe L, Mookherjee N, Slater J, Slivinski C, Singer M, Whaley C, Denechezhe L, Matyas S, Turner-Brannen E, Nickerson P and Orr P: Vitamin D in a northern Canadian first nation population: Dietary intake, serum concentrations and functional gene polymorphisms. PLoS One 7: e49872, 2012.

18. Uitterlinden AG, Fang Y, Van Meurs JB, Pols HA and Van Leeuwen JP: Genetics and biology of vitamin D receptor polymorphisms. Gene 338: 143-156, 2004.

19. Lee JJ, Wu X, Hildebrandt MA, Yang H, Khuri FR, Kim E, Gu J, Ye Y, Lotan R, Spitz MR and Hong WK: Global assessment of genetic variation influencing response to retinoid chemoprevention in head and neck cancer patients. Cancer Prev Res (Phila) 4: 185-193, 2011.

20. No authors listed: Revised American Society for Reproductive Medicine classification of endometriosis: 1996. Fertil Steril 67: 817-821, 1997

21. Szczepańska M, Wirstlein P, Skrzypczak J and Jagodziński PP: Polymorphic variants of CYP17 and CYP19A and risk of infertility in endometriosis. Acta Obstet Gynecol Scand 92:1188-1193, 2013.

22. Aljanabi SM and Martinez I: Universal and rapid salt-extraction of high quality genomic DNA for PCR-based techniques. Nucleic Acids Res 25: 4692-4693, 1997.

23. Dudbridge F: Pedigree disequilibrium tests for multilocus haplotypes. Genet Epidemiol 25: 115-121, 2003.

24. Hahn LW, Ritchie MD and Moore JH: Multifactor dimensionality reduction software for detecting gene-gene and gene-environment interactions. Bioinformatics 19: 376-382, 2003.

25. Maruotti N and Cantatore FP: Vitamin D and the immune system. J Rheumatol 37: 491-495, 2010.

26. Parikh G, Varadinova M, Suwandhi P, Araki T, Rosenwaks Z, Poretsky L and Seto-Young D: Vitamin D regulates steroidogenesis and insulin-like growth factor binding protein-1 (IGFBP-1) production in human ovarian cells. Horm Metab Res 42: 754-757, 2010.
27. Grundmann $\mathrm{M}$ and von Versen-Höynck F: Vitamin D-roles in women's reproductive health? Reprod Biol Endocrinol 9: 146, 2011.

28. Anagnostis P, Karras S and Goulis DG: Vitamin D in human reproduction: A narrative review. Int J Clin Pract 67: 225-235, 2013.

29. Abbas MA, Taha MO, Disi AM and Shomaf M: Regression of endometrial implants treated with vitamin D3 in a rat model of endometriosis. Eur J Pharmacol 715: 72-75, 2013.

30. Yildirim B, Guler T, Akbulut M, Oztekin O and Sariiz G: 1-alpha,25-dihydroxyvitamin D3 regresses endometriotic implants in rats by inhibiting neovascularization and altering regulation of matrix metalloproteinase. Postgrad Med 126: 104-110, 2014.

31. Vilarino FL, Bianco B, Lerner TG, Teles JS, Mafra FA, Christofolini DM and Barbosa CP: Analysis of vitamin D receptor gene polymorphisms in women with and without endometriosis. Hum Immunol 72: 359-363, 2011.

32. Luo XY, Yang MH, Wu FX, Wu LJ, Chen L, Tang Z, Liu NT, Zeng XF, Guan JL and Yuan GH: Vitamin D receptor gene BsmI polymorphism $\mathrm{B}$ allele, but not $\mathrm{BB}$ genotype, is associated with systemic lupus erythematosus in a Han Chinese population. Lupus 21: 53-59, 2012.

33. Arai H, Miyamoto K, Taketani Y, Yamamoto H, Iemori Y, Morita K, Tonai T, Nishisho T, Mori S and Takeda E: A vitamin $\mathrm{D}$ receptor gene polymorphism in the translation initiation codon: Effect on protein activity and relation to bone mineral density in Japan women. J Bone Miner Res 12: 915-921, 1997.

34. Monticielo OA, Brenol JC, Chies JA, Longo MG, Rucatti GG, Scalco R and Xavier RM: The role of BsmI and FokI vitamin D receptor gene polymorphisms and serum 25 -hydroxyvitamin $\mathrm{D}$ in Brazilian patients with systemic lupus erythematosus. Lupus 21: 43-52, 2012.

35. Agic A, Xu H, Altgassen C, Noack F, Wolfler MM, Diedrich K, Friedrich M, Taylor RN and Hornung D: Relative expression of 1,25-dihydroxyvitamin D3 receptor, vitamin $D 1$ alpha-hydroxylase, vitamin D 24-hydroxylase and vitamin D 25-hydroxylase in endometriosis and gynecologic cancers. Reprod Sci 14: 486-497, 2007.

36. Zelenko Z, Aghajanova L, Irwin JC and Giudice LC: Nuclear receptor, coregulator signaling and chromatin remodeling pathways suggest involvement of the epigenome in the steroid hormone response of endometrium and abnormalities in endometriosis. Reprod Sci 19: 152-162, 2012

37. Smolikova K, Mlynarcikova A and Scsukova S: Effect of 1 $\alpha, 25$-dihydroxyvitamin D3 on progesterone secretion by porcine ovarian granulosa cells. Endocr Regul 47: 123-131, 2013.

38. Mariani M, Viganò $\mathrm{P}$, Gentilini $\mathrm{D}$, Camisa $\mathrm{B}$, Caporizzo E, Di Lucia P, Monno A, Candiani M, Somigliana E and Panina-Bordignon P: The selective vitamin D receptor agonist, elocalcitol, reduces endometriosis development in a mouse model by inhibiting peritoneal inflammation. Hum Reprod 27: 2010-2019, 2012 